\title{
Glacier Monitoring Using Sensor Techniques Powered by Renewable Energy Resources: A Prototype
}

\author{
MisbahNoorain N, Syed Thouheed Ahmed, H G Shenoy, Syed Ariff \\ Dr. T Thimmaiah Institute of Technology, Karnataka, India \\ syed@drttit.edu.in
}

\begin{abstract}
Glaciers - The "rivers of ice" in the Indian Himalayas are one of the important environmental and economic formation that gives service by releasing melted fresh water for the Northern and North-Eastern part of our country throughout the dry season. Glaciological studies conducted at a very high altitude and under adverse weather conditions such as in the highlands of the Himalayas are difficult in the usual ways. As Glacier changes, especially the changes in mountain glaciers, are one of the most sensitive indicators of terrestrial climate change. Thereby the observations from the present day be a sign of that the gradual change in the global climatic conditions is a major cause of the natural disasters which we are witnessing these days. This calls for an informative approach towards studying the dynamics of this huge river of slowly moving ice. Therefore, the monitoring of glacial changes has been the subject of much research interest. Thus, our project aims to monitor the various parameters like water temperature, surface temperature, humidity and water level by using GPS we are having the track of the movement of the Glacier and then connecting it to the IOT and then we are fetching the data away from site which are concerned towards the retreat of Siachen glacier by using renewable energy sources, since Glacier siachen is home for our Indian army, it's been a subject of research to us.
\end{abstract}

Keywords:Alert, Glaciers, IOT, Monitoring, Sensors.

\section{$1 \quad$ Introduction}

Climatic conditions and the change at the global level and sustainable environmental friendly development are the two major focuses in current geographical studies. By observing these changes, [1][2] it has been determined that one of the major causes of natural disaster is the gradual changing of global climate parameters. [3] The Indian Himalayan mountain range consists of one of the largest collections of the glaciers outside the Polar Regions, with a total glacier covering of 33,000 km2 and around 9600 glaciers exist in the Indian Himalaya. The Himalayan glaciers being one of the most important sources of fresh water to the Indian subcontinent consist of the count- 
less rivers that flow across the Indo-Gangetic plains. The rivers that gush across countryside borders and meet the need of potable water and also help in , irrigation, hydropower, fishery, inland navigation and other water related requirements of more than 1.3 billion people living in the area around the mountains, valleys and the plains along its path. With a large number of small and large glaciers in the Himalayas, the number being 9,575, and they are the largest reserves of water in the form of ice and snow outside the Polar Regions. That is the reason for the Himalayas being referred to as the 'water towers' of Asia and a 'third pole' of the earth. [4][6]

'The Monitoring of glaciers actuates scientific concern for two main reasons. First, Climate change research requires constant monitoring of the changes in glacier parameters. [5] [9] The future of water availability can survive likely by monitoring the surface area and volume of individual glaciers. Second, for public, industrial and hydroelectric power generation purposes glaciers in Indian Himalayas have been known as crucial water storage systems. Since the study of glacier physics and dynamics is a huge inspiration for research, this will help us in understanding glaciers better as well as the essential dynamics of it. [7][10] However the presence of large amount of debris affects the observation of these remote glaciers and their study.

\section{Proposed Methodology}

The main focus is to study glacier conditions like surface temperature, under water temperature, humidity, water level and movement of the glacier using both GPS and IOT technologies. Have an early alert in case of conditions arising to Outburst Floods as it has become the imminent danger of the current number of neighbors of these receding glaciers. In our project we monitor the various parameters of glacier by using the IOT (Internet of Things), In general the parameters can be monitored by three ways, the first one is by radio frequency, the second type is by the GSM method, and by the IOT. But our project operates completely on the IOT where it has several advantages than compared with the Radio frequency method and the GSM method. Because our project aims at monitoring the glacier parameters away from the site, it is much convenient to use the IOT which makes the system to work efficiently by getting the data from long distance as well it can be used to get the real time data which avoids the offline data overcoming the drawback of the other two methods. [8]

The data of glacio-parameters are fetched by various sensors, the output of which can be sent to far away location by using the trans-receiver which in turn sends it to the cloud server. By using IOT technologies, data from cloud server is accessed by the smart phone (output device). By implementing GPS (Global Positioning System) technologies we are able to track the location of the glacier. The glaciers have warm days and cold nights, considering this condition our model is energized by the solar module during day and by the wind energy during night to power the various equipments.

- Acquiring the data

- Processing the data through IOT

- Conditional Monitoring and alert generation 


\subsection{Block Diagram}

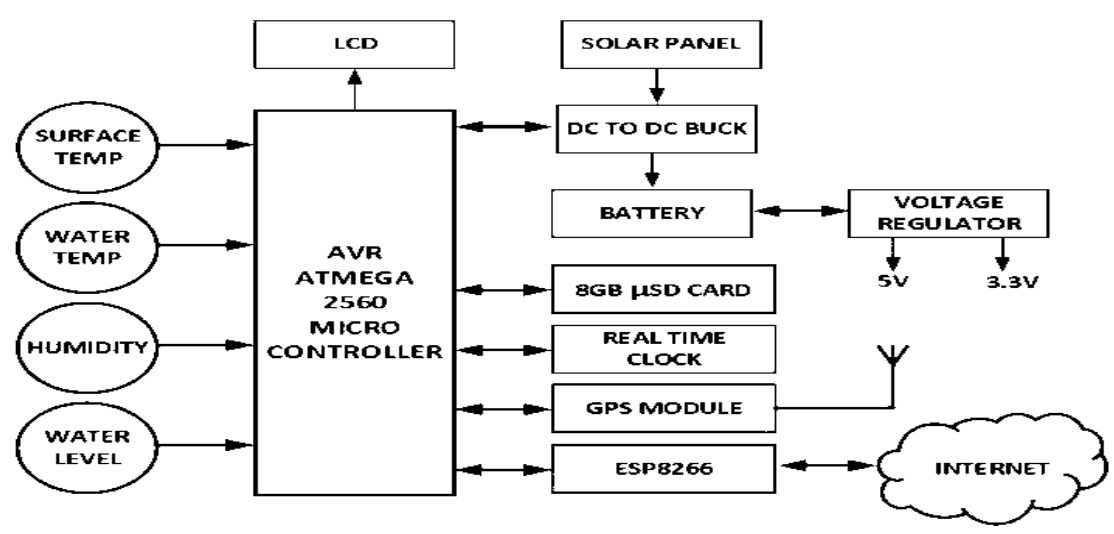

Fig 2: Hardware model

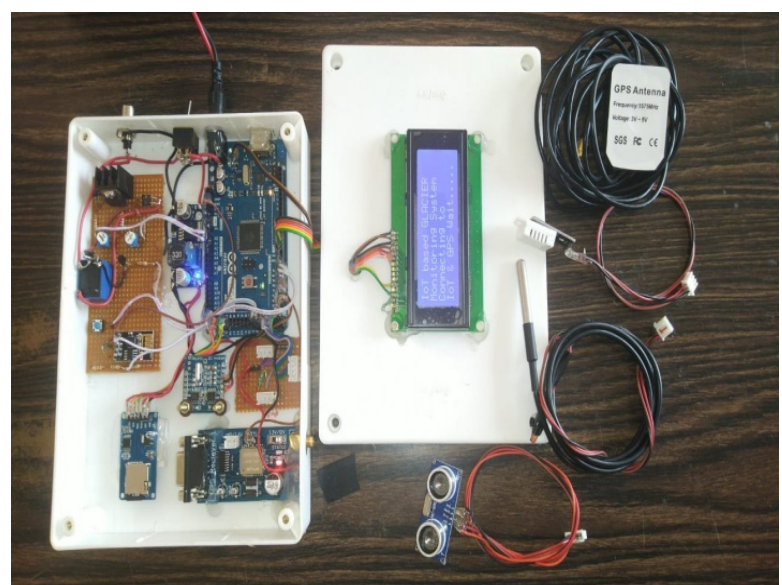

\section{Implementation}

Once the module is built we have to obtain the data far away from the site. This is done by connecting the module to the IOT. Coming to IOT it is connecting the module to the server so that there is transfer of data to and from the module and to track the values of various parameters. To obtain the data to our mobile device we use a 
WiFitrans receiver. The module is powered by the energy from solar cell. Sequence of operation follows as,

\begin{tabular}{|l|l|l|r|r|r|r|r|c|c|}
\hline Date & Time & H2O & Rur & RH & $\begin{array}{c}\text { L } \\
\text { evel }\end{array}$ & Batt & SP & Lat & Long \\
\hline $24 / 06 / 2020$ & $16: 47: 34$ & 7 & 30 & 54.40 & 8 & 12.10 & 0.07 & 12.968710 & 78.257828 \\
\hline $24 / 06 / 2020$ & $16: 47: 38$ & 7 & 30 & 54.60 & 8 & 12.14 & 0.08 & 12.968710 & 78.257828 \\
\hline $24 / 06 / 2020$ & $16: 47: 43$ & 7 & 30 & 54.50 & 8 & 12.13 & 0.06 & 12.968710 & 78.257828 \\
\hline $24 / 06 / 2020$ & $16: 47: 50$ & 7 & 30 & 54.50 & 8 & 12.14 & 0.07 & 12.968710 & 78.257828 \\
\hline $24 / 06 / 2020$ & $16: 47: 58$ & 7 & 30 & 54.50 & 8 & 12.13 & 0.07 & 12.968710 & 78.257828 \\
\hline $24 / 06 / 2020$ & $16: 48: 5$ & 7 & 30 & 54.50 & 8 & 12.14 & 0.08 & 12.968710 & 78.257828 \\
\hline $24 / 06 / 2020$ & $16: 48: 12$ & 7 & 30 & 54.40 & 8 & 12.14 & 0.06 & 12.968710 & 78.257828 \\
\hline $24 / 06 / 2020$ & $16: 48: 19$ & 7 & 30 & 54.40 & 8 & 12.14 & 0.06 & 12.968710 & 78.257828 \\
\hline $24 / 06 / 2020$ & $16: 48: 51$ & 7 & 30 & 54.40 & 8 & 12.12 & 0.09 & 12.968710 & 78.257828 \\
\hline $24 / 06 / 2020$ & $16: 48: 58$ & 7 & 30 & 54.40 & 8 & 12.15 & 0.09 & 12.968710 & 78.257828 \\
\hline $24 / 06 / 2020$ & $16: 49: 4$ & 7 & 30 & 54.30 & 8 & 12.14 & 0.09 & 12.968710 & 78.257828 \\
\hline $24 / 06 / 2020$ & $16: 49: 11$ & 7 & 30 & 54.40 & 8 & 12.16 & 0.10 & 12.968710 & 78.257828 \\
\hline
\end{tabular}

The Module waits for hotspot (internet connection) and GPS network. The Blynk app is installed and the authentication is done to get the connectivity, after connecting to the module, the status notification is received to the mobile through Blynk app. The data's from various sensors are displayed on LCD screen and also fetched to the mobile through Blynk app, by having a track of the data of the year we can be able to predict the future weather condition of the year. 


\begin{tabular}{|l|l|l|l|l|l|l|l|l|l|}
\hline $24 / 06 / 2020$ & $16: 49: 18$ & 7 & 30 & 54.50 & 8 & 12.13 & 0.09 & 12.968710 & 78.257828 \\
\hline $24 / 06 / 2020$ & $16: 49: 25$ & 7 & 30 & 54.50 & 8 & 12.14 & 0.10 & 12.968710 & 78.257828 \\
\hline $24 / 06 / 2020$ & $16: 49: 32$ & 6 & 30 & 54.60 & 8 & 12.15 & 0.10 & 12.968710 & 78.257828 \\
\hline $24 / 06 / 2020$ & $16: 49: 39$ & 6 & 30 & 54.50 & 8 & 12.17 & 0.08 & 12.968710 & 78.257828 \\
\hline $24 / 06 / 2020$ & $16: 49: 46$ & 6 & 30 & 54.40 & 8 & 12.15 & 0.11 & 12.968710 & 78.257828 \\
\hline $24 / 06 / 2020$ & $16: 49: 53$ & 6 & 30 & 54.40 & 8 & 12.15 & 0.09 & 12.968710 & 78.257828 \\
\hline $24 / 06 / 2020$ & $16: 49: 58$ & 6 & 30 & 54.40 & 8 & 12.15 & $0.09 \mathrm{~s}$ & 12.968710 & 78.257828 \\
\hline
\end{tabular}

Table 1.Data recorded during demo

\begin{tabular}{|l|l|l|l|}
\hline PARTICULARS & $\begin{array}{c}\text { AT NORMAL ROOM } \\
\text { TEMPERATURE }\end{array}$ & $\begin{array}{c}\text { AT REFRIGERATOR } \\
\text { TEMPERATURE }\end{array}$ & $\begin{array}{c}\text { FOR TEMPERATURE } \\
\text { HIGH(ALERT GENERATED) }\end{array}$ \\
\hline Water temperature & $31^{\circ} \mathrm{C}$ & $6^{\circ} \mathrm{C}$ & $35^{\circ} \mathrm{C}$ \\
\hline $\begin{array}{l}\text { Surface water tem- } \\
\text { perature }\end{array}$ & $31^{\circ} \mathrm{C}$ & $30^{\circ} \mathrm{C}$ & $30^{\circ} \mathrm{C}$ \\
\hline Humidity & $49.50 \%$ & $51.40 \%$ & $51.20 \%$ \\
\hline Water Level & 2 & 0 & 12 \\
\hline Battery & $12.06 \mathrm{~V}$ & $12.14 \mathrm{~V}$ & $0.16 \mathrm{~V}$ \\
\hline Solar Panel & $0.15 \mathrm{~V}$ & $0.12 \mathrm{~V}$ & $20: 0: 10$ \\
\hline Time & $18: 58: 22$ & $20: 13: 47$ & $23 / 06 / 2020$ \\
\hline Date & $23 / 06 / 2020$ & $23 / 06 / 2020$ & 12.968664 \\
\hline Latitude & 12.968664 & 12.968664 & 78.257705 \\
\hline Longitude & 78.257705 & 78.257705 & Halted \\
\hline Solar charging & Halted & Halted & \\
\hline
\end{tabular}

\section{$4 \quad$ Results}

The data that we monitor are the various parameters of glacier as stated earlier and by using the developed model (fig 2: Hardware model) and uploading the code into the kit the following results are obtained.

4.1 Stored data obtained from memory card (for a given period):

$\mathrm{H}_{2} \mathrm{O}$ - Water ; Sur- Surface Temperature; RH - Humidity; Batt- Battery ; SP- Solar Panel; Lat- Latitude; Long- Longitude 


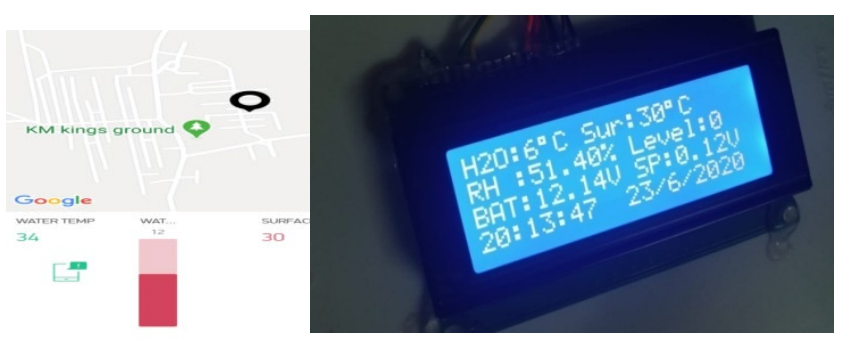

Fig 3: (Left) Displays the values on mobile through BLYNK app (Right) Displays the monitored values on LCD screen

\section{Conclusion}

The prime focus of collecting the glacier conditions like surface temperature, under water temperature, humidity, water level and movement of the glacier using both GPS and IOT technologies was achieved. And we have collected the data under observation of model of glacier conditions and recorded all the parameters which are mentioned above and have successfully recorded. With various data from the sensors and in case of exceeding values the alarm is generated and early alert in case of conditions arising to Outburst Floods is given and as it has become a alarming threat for the residents in current neighborhood of these retreating glaciers.

\section{Reference}

1. P. Pellika and w.g. Rees, eds. remote sensing of glaciers: techniques for topographic, spatial, and thematic mapping of glacier. (2010).

2. Zemp et al., reanalyzing glacier mass balance measurement series. (2013)

3. Bamber and Rivera, a review of remote sensing methods for glacier mass balance determination,(2007)

4. Kargel et al. 2005, response of glacier and lake co variations to climate change in mapamyumco basin on Tibetan plateau during 1974-2003(2005) karpilo, glacier monitoring techniques(2009)

5. Molina 2006, recent glacier retreat and climate trends in cordillera huaytapallana, Peru (2006).

6. Kumar, S.S., Ahmed, S.T., Vigneshwaran, P. et al. "Two phase cluster validation approach towards measuring cluster quality in unstructured and structured numerical datasets". J Ambient Intell Human Comput (2020). https://doi.org/10.1007/s12652-020-02487-w

7. Ahmed, S.T., Sankar, S. \& Sandhya, M. "Multi-objective optimal medical data informatics standardization and processing technique for telemedicine via machine learning ap- 
proach". J Ambient Intell Human Comput (2020). https://doi.org/10.1007/s12652-02002016-9

8. Gunashree, M., Ahmed, S. T., Sindhuja, M., Bhumika, P., Anusha, B., \&Ishwarya, B. (2020). A New Approach of Multilevel Unsupervised Clustering for Detecting Replication Level in Large Image Set. Procedia Computer Science, 171, 1624-1633. https://doi.org/10.1016/j.procs.2020.04.174

9. K. Pradeep Mohan Kumar, M. Saravanan, M. Thenmozhi ,K. Vijayakumar, “ Intrusion detection system based on GA-fuzzy classifier for detecting malicious attacks", wiley, Feb 2019.

10. R. Joseph Manoj, M. D. Anto Praveena, K. Vijayakumar, "An ACO-ANN based feature selection algorithm for big data", Cluster computing, springer,march 2018. 